\title{
a)
}

Asian Journal of Animal and Veterinary Advances

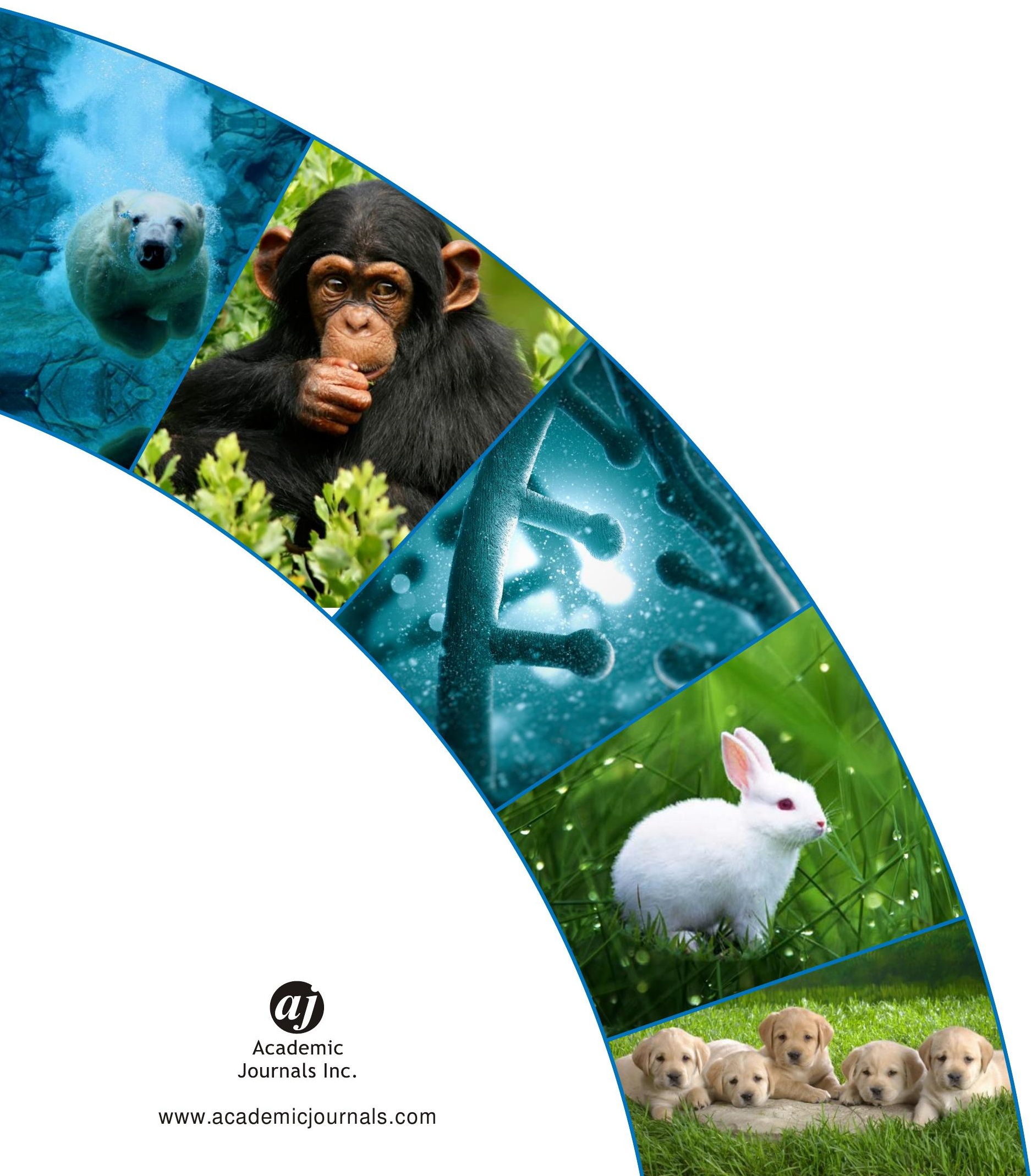




\title{
Research Article
}

\section{Raw Allium sativum as Performance Enhancer and Hypocholesterolemic Agent in Laying Hens}

\author{
${ }^{1}$ Funmilayo Grace Adebiyi, ${ }^{2}$ Anthony Durojaiye Ologhobo and ${ }^{3}$ Isaac Oluseun Adejumo \\ ${ }^{1}$ College of Medicine, University of Ibadan, Ibadan, Nigeria \\ ${ }^{2}$ Animal Biochemistry and Nutrition Research Unit, Department of Animal Science, University of Ibadan, Ibadan, Nigeria \\ ${ }^{3}$ Animal Nutrition, Biotechnology and Food Safety Laboratory, Department of Animal Science, Federal University Gashua, Gashua, Nigeria
}

\section{Abstract}

Background and Objective: Nutritionally, poultry eggs are referred to compete protein owing to their amino acid profile. However, consumption of egg is usually with caution because they are rich sources of cholesterol in human diets. Consumption of cholesterol-rich diet has a positive correlation with increased serum total and low-density lipoprotein cholesterol (LDL) concentrations both in human and animals. High serum total and LDL levels have been associated with increased deposition of fat around the arterial walls which could result in increased incidence of atherosclerosis and coronary heart diseases. This study was carried out to investigate raw Allium sativum as performance enhancer and hypocholesterolemic agent in laying hens. Materials and Methods: The efficacy of raw garlic (RG) as performance booster and cholesterol-lowering agent in laying hens was investigated in a 20 weeks feeding trial. Eighteen weeks old Isa Brown hens $(n=180)$ were randomly distributed to 6 dietary treatments. Each dietary treatment consisted of 6 replicates of 5 birds each. The serum samples were analyzed for total cholesterol (TC), triglycerides (Tg) and high-density lipoprotein cholesterol (HDL) using randox kit. Data were analyzed by one-way analysis of variance (ANOVA) using SPSS version 16 and the means were separated using Duncan's multiple range test of the same software. Results: Five percent RG inclusion resulted in reduced feed intake in the experimental laying hens while $2 \%$ inclusion of RG had the highest hen-house production. The highest hypocholesterolemic effect of RG was observed in birds fed 3\% RG (79 $\left.\mathrm{mg} \mathrm{dL}^{-1}\right)$, followed by birds fed with 2, 4, 1 and 5\% RG, respectively. The effect of inclusion of RG in the diets of laying on TC was similar for birds fed with 2, 3 and 4\% RG. Conclusion: The RG inclusion improved high-density lipoprotein cholesterol but reduced total cholesterol contents in the experimental animals.

Key words: Allium sativum, atherosclerosis, cholesterol, lipoprotein, raw garlic

Received: August 30, 2017

Accepted: November 29, 2017

Published: April 15, 2018

Citation: Funmilayo Grace Adebiyi, Anthony Durojaiye Ologhobo and Isaac Oluseun Adejumo, 2018. Raw Allium sativum as performance enhancer and hypocholesterolemic agent in laying hens. Asian J. Anim. Vet. Adv., 13: 210-217.

Corresponding Author: Isaac Oluseun Adejumo, Animal Nutrition, Biotechnology and Food Safety Laboratory, Department of Animal Science, Federal University Gashua, Gashua, Nigeria Tel: +2348066446246

Copyright: @ 2018 Funmilayo Grace Adebiyi et al. This is an open access article distributed under the terms of the creative commons attribution License, which permits unrestricted use, distribution and reproduction in any medium, provided the original author and source are credited.

Competing Interest: The authors have declared that no competing interest exists.

Data Availability: All relevant data are within the paper and its supporting information files. 


\section{INTRODUCTION}

Poultry eggs have been held up as a powerhouse of nutrition. This reputation is due to egg's exceptional nutritional profile as a nutrient-dense food containing high quality protein and substantial amounts of many essential vitamins and minerals. Unfortunately, their position on the nutrition pedestal fell with the discovery that they are a major source of dietary cholesterol'. The cholesterol is deposited mainly in the egg yolk, which represents about one-third of the egg content by weight.

Despite the important contribution of eggs in human diets and the fact that eggs are low-cost sources of protein and certain vitamins, consumption of egg is usually with caution because poultry eggs are rich sources of cholesterol in human diets. Consumption of cholesterol rich diet has a positive correlation with increased serum total and low-density lipoprotein cholesterol (LDL) concentrations both in human and animals ${ }^{2-3}$. High serum total and LDL levels have been associated with increased deposition of fat around the arterial walls. This results is increased incidence of atherosclerosis and coronary heart diseases ${ }^{4}$. Among 514 Australian aborigines, consumption of $>2$ eggs/week was associated with a 2.6 times greater risk of coronary artery disease in a prospective analysis ${ }^{5}$. While a report of meta-analysis by Weggemans et al. ${ }^{6}$ indicated that consumption of an egg/day increases heart disease risk by $2.1 \%$.

Garlic (Allium sativum) is widely distributed and used in all parts of the world as a spice. It is also one of the most popular herbal remedies worldwide today. Garlic and its preparations have been widely recognized as agent for prevention and treatment of cardiovascular and other metabolic diseases, atherosclerosis, hypertension, thrombosis and diabetes. Allicin has been suggested as the potentially active component of garlic?.

Animal studies suggested that garlic paste (3.8\%), solvent-extracted fractions of garlic or garlic oil equivalent reduced the amount of serum cholesterol by 18 and $23 \%$ in broilers and 12 weeks-old Leghorn pullets, respectively ${ }^{8}$. Sklan et al. ${ }^{9}$ observed depressed hepatic cholesterol concentration in chickens fed with $2 \%$ garlic while similar effects were found in rats ${ }^{10}$. Garlic extract fed to 5 weeks-old male broilers also exhibited hypocholesterolemic effects, mainly through the inhibition of the key enzymes ${ }^{8}$. Fresh garlic polysaccharide has been observed to exhibit immunomodulatory activities ${ }^{11}$. However, there is a paucity of information on the effect of inclusion of raw garlic in layers' diets on lipid metabolism and performance of laying hens.
Therefore, the study was conducted to investigate the efficacy of raw garlic as performance booster and lipid-reducing agent in laying hens.

\section{MATERIALS AND METHODS}

The experimental protocol and feeding trial was carried out in accordance with the Principles of Laboratory Animal Care (NIH publication No. 85-23, revised 1985) and as approved by the Animal Ethics Committee, Department of Animal Science, University of Ibadan, Nigeria. The study was conducted between January and April, 2015. The study adopted a completely randomized experimental design with six treatments. Treatment 1 was the control with $0 \%$ level of garlic while treatments 2-6 had 1,2,3,4 and 5\% inclusion level of raw garlic paste. The garlic used for the study was obtained from Sokoto, Northern part of Nigeria. The garlic was separated into cloves and ground into paste. The composition of the basal diet is shown in Table 1.

Management of experimental birds: Eighteen weeks old Isa Brown hens $(n=180)$ were randomly distributed to 6 dietary treatments. Each dietary treatment consisted of 6 replicates of 5 birds each. The birds were housed in galvanized iron cages under an intensive management system and the birds were allowed to acclimatize for 2 weeks and the study spanned over a 20 weeks period. Feed and water were given ad libitum.

Performance parameters measured: Feed consumption was obtained by finding the difference between the quantity of given feed/week and the left over. The body weight of each bird was taken at the start of the experiment. After which the body weights for each bird were measured every 4 weeks. The eggs laid were collected twice a day (i.e., morning and evening). The egg weights were measured daily. The percentage hen-day production was determined from the daily egg production records ${ }^{12}$ :

$$
\text { Hen-day production }(\%)=\frac{\text { Total Number of egg laid }}{\text { Number of birds } \times \text { Number of days }} \times 100
$$

The egg mass was calculated as follows:

$$
\text { Egg mass }=\frac{\text { Egg production } \times \text { egg weight }}{100}
$$

Feed efficiency was measured thus:

$$
\text { Feed efficiency }=\frac{\text { Feed intake }(\mathrm{g})}{\text { Egg mass }} \times 100
$$


Asian J. Anim. Vet. Adv., 13 (3):210-217, 2018

Table 1: Composition of diet fed to experimental birds

\begin{tabular}{|c|c|c|c|c|c|c|}
\hline Ingredients & $1(0 \%)$ & 2 (1\% RG) & $3(2 \%$ RG) & 4 (3\% RG) & 5 (4\% RG) & $6(5 \%$ RG) \\
\hline Maize & 44.5 & 45.0 & 46.5 & 47.0 & 47.5 & 48.0 \\
\hline Palm kernel cake & 9.0 & 9.0 & 8.0 & 8.0 & 8.0 & 8.0 \\
\hline Corn bran & 8.0 & 8.0 & 7.0 & 6.0 & 5.0 & 4.0 \\
\hline Wheat bran & 9.5 & 7.0 & 6.0 & 5.0 & 4.0 & 3.0 \\
\hline Groundnut cake & 7.0 & 8.0 & 8.5 & 9.5 & 10.5 & 11.5 \\
\hline Soybean cake & 9.5 & 9.5 & 9.5 & 9.0 & 8.5 & 8.0 \\
\hline Raw garlic & 0.0 & 1.0 & 2.0 & 3.0 & 4.0 & 5.0 \\
\hline Fish meal & 2.0 & 2.0 & 2.0 & 2.0 & 2.0 & 2.0 \\
\hline Bone meal & 3.0 & 3.0 & 3.0 & 3.0 & 3.0 & 3.0 \\
\hline Oyster shell & 6.6 & 6.6 & 6.6 & 6.6 & 6.6 & 6.6 \\
\hline Salt & 0.25 & 0.25 & 0.25 & 0.25 & 0.25 & 0.25 \\
\hline Vitamin premix & 0.25 & 0.25 & 0.25 & 0.25 & 0.25 & 0.25 \\
\hline Methionine & 0.25 & 0.25 & 0.25 & 0.25 & 0.25 & 0.25 \\
\hline Lysine & 0.15 & 0.15 & 0.15 & 0.15 & 0.15 & 0.15 \\
\hline Total & 100.00 & 100.00 & 100.00 & 100.00 & 100.00 & 100.00 \\
\hline \multicolumn{7}{|l|}{ Calculated analysis } \\
\hline Crude protein (\%) & 17.07 & 17.14 & 17.06 & 17.07 & 17.08 & 17.09 \\
\hline Metabolizable energy $\left(\mathrm{kcal} \mathrm{kg}^{-1}\right)$ & 2600.00 & 2596.50 & 2596.10 & 2582.50 & 2568.90 & 2555.20 \\
\hline
\end{tabular}

Eggs collected from each bird in each treatment at weeks $5,10,15$ and 20 of the study were used for the measurements of internal and external egg quality parameters. The weight of eggs laid by the birds in each replicate was measured using a sensitive electronic scale. The weight of the shell was taken with a sensitive electronic scale. The egg shell thickness was taken using micrometer screw gauge. The egg yolk was separated from the albumen and the weight was also measured using an electronic scale. The yolk colour was determined using the colour range of Rouche colour fan numbered 1-15 while the yolk height was determined by the use of a vernier caliper. The vernier caliper was also used to measure the egg diameter.

Blood collection and analysis: Blood samples were collected from the birds at weeks 10 and 20 through the jugular vein. Blood samples for serum lipid analysis were collected in a sterile plain test tube, they were allowed to clot and then centrifuged at $2000 \mathrm{rpm}$ for $10 \mathrm{~min}$. The sera samples were carefully removed using pasture pipette and were stored at $-20^{\circ} \mathrm{C}$ until further analysis.

Analysis of serum lipids: The serum samples were analyzed for total cholesterol (TC), triglycerides ( $\mathrm{Tg}$ ) and high-density lipoprotein cholesterol (HDL) using randox kit (CH201, TR210 and $\mathrm{CH} 203$, respectively, Randox Laboratories Limited, Antrim, UK). The LDL was calculated using Friedewald equation ${ }^{13}$ :

$$
\mathrm{LDL}=\mathrm{TC}-(\mathrm{HDL})-\frac{\mathrm{Tg}}{5}
$$

Collection of egg yolk: Eggs used for analysis of yolk cholesterol were collected from each bird at 10th and 20th weeks of the experiment. The yolk was carefully separated from the albumen using a separating pan. The samples were stored at $-20^{\circ} \mathrm{C}$ until analysis.

Extraction and analysis of eggyolk cholesterol: One gram of yolk was placed into a centrifuge tube. Twenty milliliters of chloroform:methanol (2:1) was added, blended on a vortex mixture. A $10 \mathrm{~L}$ volume of the clear extract was used for the assay of total cholesterol. Cholesterol assay kit by Dialab (D00119, Dialab GmbH, Austria) was used for the cholesterol estimation.

Statistical analysis: Data were analyzed by one-way analysis of variance (ANOVA) using SPSS (Version 16.0. Armonk, NY: IBM Corp.)and the means were separated using Duncan's multiple range test of the same software. Values were expressed as mean (standard error of mean (SEM)). The level of statistical significance was $p<0.05$.

\section{RESULTS}

Effect of dietary inclusion of varying levels of raw garlic on the performance of laying hens is shown in Table 2. Birds fed 1 and $3 \%$ RG consumed slightly higher feed than birds fed the control diet, although the values were statistically similar. However, there was a significant decrease of $6.5 \%$ in the average daily feed intake of birds fed $5 \%$ RG compared with those fed with control diets. There was no significant difference in feed efficiency among all the treatment groups. 
Asian J. Anim. Vet. Adv., 13 (3):210-217, 2018

Table 2: Effect of dietary inclusion of varying levels of raw garlic on the performance of laying hens

\begin{tabular}{|c|c|c|c|c|c|c|}
\hline \multirow[b]{2}{*}{ Parameters } & \multicolumn{6}{|l|}{ Treatments } \\
\hline & Control diet & $1 \%$ garlic & $2 \%$ garlic & $3 \%$ garlic & $4 \%$ garlic & $5 \%$ garlic \\
\hline Average daily feed intake (g/bird) & $99.70(0.57)^{\mathrm{ab}}$ & $101.60(0.45)^{\mathrm{a}}$ & $99.70(1.06)^{\mathrm{ab}}$ & $101.60(0.96)^{\mathrm{a}}$ & $98.10(0.35)^{b}$ & $93.20(1.21)^{c}$ \\
\hline Feed efficiency* & $2.51(0.208)$ & $2.34(0.123)$ & $2.51(0.150)$ & $2.81(0.148)$ & $2.57(0.061)$ & $2.69(0.257)$ \\
\hline Average egg/weight $(\mathrm{g})^{*}$ & $61.30(1.31)$ & $59.90(1.18)$ & $60.80(0.86)$ & $63.20(0.94)$ & $60.20(1.03)$ & $59.10(1.12)$ \\
\hline Hen day production (\%) & $66.90(3.27)^{\mathrm{ab}}$ & $71.50(1.98)^{\mathrm{bc}}$ & $77.40(1.83)^{c}$ & $70.70(2.75)^{\mathrm{bc}}$ & $63.20(2.43)^{\mathrm{a}}$ & $66.30(1.81)^{\mathrm{ab}}$ \\
\hline Egg mass (g/day/hen)* & $40.90(3.56)$ & $43.90(1.95)$ & $40.50(3.01)$ & $36.60(2.34)$ & $38.30(0.82)$ & $36.00(3.52)$ \\
\hline
\end{tabular}

${ }^{*}$ Not significant, means with the same superscript in horizontal row are not significantly different $(p<0.05)$

Table 3: Effect of dietary inclusion of varying levels of raw garlic on the egg quality parameters

\begin{tabular}{|c|c|c|c|c|c|c|}
\hline \multirow[b]{2}{*}{ Parameters } & \multicolumn{6}{|l|}{ Treatments } \\
\hline & Control diet & $1 \%$ garlic & $2 \%$ garlic & $3 \%$ garlic & $4 \%$ garlic & $5 \%$ garlic \\
\hline Egg weight (g) & $61.40^{\mathrm{ab}}$ & $59.90^{\mathrm{b}}$ & $60.80^{\mathrm{ab}}$ & $63.20^{\mathrm{a}}$ & $60.70^{\mathrm{ab}}$ & $59.10^{\mathrm{b}}$ \\
\hline Yolk weight (g)* & 15.84 & 16.06 & 16.16 & 15.85 & 16.23 & 15.96 \\
\hline Shell weight $(g)^{*}$ & 8.18 & 7.93 & 7.93 & 7.97 & 7.84 & 7.95 \\
\hline Shell thickness $(\mathrm{mm})^{*}$ & 0.55 & 0.56 & 0.56 & 0.56 & 0.55 & 0.55 \\
\hline Yolk height & $1.68^{b, c}$ & $1.73^{\mathrm{a}, \mathrm{b}}$ & $1.76^{\mathrm{a}, \mathrm{b}}$ & $1.83^{\mathrm{a}}$ & $1.61^{c}$ & $1.73^{\mathrm{ab}}$ \\
\hline Egg length & $5.89^{a, b}$ & $5.87^{b}$ & $5.90^{a, b}$ & $6.01^{a-h}$ & $6.03^{\mathrm{a}}$ & $5.97^{\mathrm{ab}}$ \\
\hline
\end{tabular}

Means with the same superscript within the same row are not significantly different ( $p>0.05),{ }^{*}$ Non-significant

Table 4: Effect of dietary inclusion of varying levels of raw garlic on the serum lipids and egg cholesterol of laying hens

\begin{tabular}{|c|c|c|c|c|c|c|}
\hline \multirow[b]{2}{*}{ Parameters } & \multicolumn{6}{|l|}{ Treatments } \\
\hline & Control diet & $1 \%$ garlic & $2 \%$ garlic & $3 \%$ garlic & $4 \%$ garlic & $5 \%$ garlic \\
\hline Cholesterol & $124.6(1.77)^{\mathrm{a}}$ & $95.0(1.33)^{b}$ & $80.3(0.92)^{c}$ & $79.0(2.75)^{c}$ & $80.5(2.51)^{c}$ & $97.6(1.51)^{b}$ \\
\hline Triglycerides & $81.3(0.51)^{\mathrm{a}}$ & $78.3(0.93)^{b}$ & $69.9(1.13)^{c}$ & $67.8(0.95)^{\mathrm{cd}}$ & $66.6(0.93)^{d}$ & $77.1(0.99)^{\mathrm{b}}$ \\
\hline HDL-cholesterol & $29.4(3.69)^{\mathrm{a}}$ & $35.6(0.83)^{b}$ & $39.5(1.26)^{c}$ & $38.5(1.45)^{c}$ & $45.2(1.87)^{d}$ & $42.3(0.88)^{\mathrm{e}}$ \\
\hline LDL-cholesterol & $78.0(2.54)^{c}$ & $44.5(2.50)^{b}$ & $26.4(1.14)^{\mathrm{a}}$ & $27.1(2.38)^{\mathrm{a}}$ & $22.9(2.23)^{\mathrm{a}}$ & $39.6(2.91)^{b}$ \\
\hline Egg yolk cholesterol $\left(\mathrm{mg} \mathrm{g}^{-1}\right)$ & $14.4(1.07)^{\mathrm{d}}$ & $12.2(0.53)^{c}$ & $11.3(0.36)^{b}$ & $11.0(0.77)^{\mathrm{ab}}$ & $10.5(0.56)^{\mathrm{a}}$ & $12.4(0.61)^{c}$ \\
\hline
\end{tabular}

Means with the same superscript in horizontal row are not significantly different $(p>0.05)$

Birds fed with $2 \%$ RG had a significant $(p<0.05)$ higher value of hen day production (HDP) compared to birds fed with the control diet, 4 and 5\% RG. The lowest HDP was observed in birds fed $4 \%$ RG although this value was not significantly different from the HDP values of birds fed with the control diets. There was no significant effect of the dietary treatments on the values for egg mass as averaged over the experimental period. Table 3 shows the effect of dietary inclusion of varying levels of raw garlic on the egg quality parameters. Intake of varying levels of raw garlic by laying hens did not have any significant effect on yolk weight, shell weight and shell thickness. The values obtained for egg weight were statistically similar across the treatments. The highest egg yolk height was recorded in bird fed 3\% RG. This value was significantly $(p<0.05)$ higher than the egg yolk height of birds fed with the control diet and 4\% RG. The values recorded for yolk height of laying chickens fed 1,2 and $5 \%$ RG were similar. The highest mean egg length was observed in chickens fed with $4 \%$ RG. Although the mean egg length of hen fed $4 \%$ RG was similar to the mean egg length of chickens fed control diet, 2, 3 and $5 \%$ RG. The birds fed $1 \%$ RG had the lowest mean egg length.
The effect of dietary inclusion of varying levels of raw garlic on the serum lipids and egg cholesterol of laying hens is presented in Table 4. The highest hypocholesterolemic effect of RG was observed in birds fed $3 \%$ RG $\left(79 \mathrm{mg} \mathrm{dL}^{-1}\right)$, followed by birds fed with 2, 4, 1 and 5\% RG, respectively. The effect of inclusion of RG in the diets of laying on TC was similar for birds fed with 2, 3 and 4\% RG. However, birds fed with 2, 3 and $4 \%$ RG had significantly $(p<0.05)$ higher value compared with birds fed with 1 and $5 \%$ RG. Birds fed control diet had the highest TC. The dietary treatments significantly $(p<0.05)$ influenced serum triglycerides of laying hens. Birds fed with $1,2,3,4$ and $5 \%$ RG had significantly $(p<0.05)$ lower Tg relative to the Tg of birds fed with the control diet. The mean values of $\mathrm{Tg}$ for birds fed with 2 and 3\% RG were similar. The lowest $\mathrm{Tg}$ was observed in birds fed with $4 \% \mathrm{RG}$ although, this value was similar to the Tg of birds fed with $3 \%$. However, the Tg of birds fed with 3 and $4 \%$ RG were significantly $(p<0.05)$ lower than the Tg of birds fed with 1 and 5\% RG. The value of Tg of birds fed with 1 and $5 \%$ RG were not significantly different.

Inclusion of graded level of garlic in layers' diets significantly $(p<0.05)$ elevated the serum HDL concentration of laying hens in comparison with the HDL of birds fed with 
the control diet. Birds fed 4\% RG recorded highest HDL concentration of $45.2 \mathrm{mg} \mathrm{dL}^{-1}$ and this value was significantly $(p<0.05)$ higher than the HDL of birds fed with other experimental diets. Although there was no significant difference in the values of $\mathrm{HDL}$ of birds fed 2 and $3 \% \mathrm{RG}$, these values were significantly $(p<0.05)$ higher than the $\mathrm{HDL}$ concentration of birds fed with $1 \% \mathrm{RG}$ and those fed with the control diet. There was an increase of 21.1, 34.4 31.0, 53.7 and 43.9\% in HDL concentration of birds fed 1, 2, 3, 4 and 5\% RG respectively when compared with the HDL of birds fed with the control diet.

A significant $(p<0.05)$ reduction in the values of $L D L$ was observed in birds fed with graded levels of RG when compared with LDL of birds fed with the control diets. The lowest LDL was recorded in birds fed 4\% RG although this value was not significantly different from LDL of layers fed with 2 and $3 \%$ RG. The LDL of layers fed with 1 and $5 \%$ were similar but were significantly $(p<0.05)$ higher than LDL of bird fed with 2, 3 and $4 \%$ RG.

A general decline of the mean egg yolk cholesterol was observed as the level RG increased up to $4 \%$ after which there was a decline of $13.4 \%$ when laying hens were fed with $5 \%$ RG relative to egg yolk cholesterol of birds fed with the control diet. There was no significant difference between egg yolk cholesterol of birds fed 1 and 5\% RG, although these values were significantly $(p<0.05)$ lower than the egg yolk of birds fed with the control diet. The egg yolk cholesterol of birds fed with 2,3 and $4 \%$ were similar.

\section{DISCUSSION}

The low feed intake of birds fed 5\% RG could be attributed to high inclusion of allicin in the diet which probably made the diet to be less acceptable to birds. Allicin is assumed to be the potential active component of garlic and increasing its concentration in diets may affect the palatability of such diets in birds ${ }^{14}$. Cullen et $a / .^{15}$ also reported a reduction in feed intake of pigs fed 1 and $10 \mathrm{~g} \mathrm{~kg}^{-1}$ garlic diet during the grower phase. The effect of inclusion of RG at varying levels in layers diets on feed intake observed in this study is in agreement with Olobatoke and Mulugeta ${ }^{16}$ who recorded a decrease in feed consumption when $5 \%$ garlic powder was included in the diet of 30 weeks-old Dekalb white strain hens.

The non-significant difference observed among the treatment groups for feed efficiency in this study shows that the inclusion of raw garlic in layers' diets up to $5 \%$ made no apparent difference in the diets that could influence the feed conversion ability of the birds. Chowdhury et al. ${ }^{17}$ earlier reported that inclusion of garlic pastes up to $10 \%$ did not have significant effect on feed efficiency.

The highest egg weight recorded for birds fed 3\% RG may be said to have a positive effect on the protein and energy utilization of the birds. Yalcin et al.18-19 reported that 5 and $10 \mathrm{~g} \mathrm{~kg}^{-1}$ of garlic powder resulted in increased egg weights of laying quails. However, garlic products did not have significant effect on egg weight in other studies ${ }^{17,20-21}$. The variations observed may be due to the use of different commercial garlic products and the preparation methods of garlic powder. The mean egg weights for all the treatment groups were above $58 \mathrm{~g}$ reported by Oluyemi and Roberts ${ }^{22}$ but were similar to that reported by Ao et al..$^{23}$ and Mohebbifar and Torki ${ }^{24}$.

The inclusion of $2 \%$ RG in layers' diet resulted in the highest value for $H D P$, which suggests that $2 \%$ level of RG may be a better level of inclusion than 0,4 and $5 \%$ RG in improving egg production of Isa Brown layers. This observation is in line with the findings of Rahardja et $a / .^{25}$ who reported significant improvement in egg production of 27 weeks Hysex Brown hens fed with $2 \%$ garlic powder. In contrast, Yalcin et al. ${ }^{18}$ reported that supplementation of layers' diet with 1, 5 and $10 \mathrm{~g} \mathrm{~kg}^{-1}$ garlic powder had no effect on egg production, which may be due to the use of very low levels of garlic powder in the diet. Similar findings as observed for egg mass in the present study were reported by Khan et al. ${ }^{26}$ for 0,2 , 6 and $8 \%$ garlic powder on 30 weeks-old Desi layers.

The result of this study revealed that RG did not result in physiological changes leading to the formation of egg yolk in laying hens. The results of this study agree with the findings of the previous studies ${ }^{18,27}$. However, Mottaghitalab and Taraz ${ }^{28}$ showed that the inclusion of 5,10 and $15 \mathrm{~g} \mathrm{~kg}^{-1}$ garlic powder decreased egg yolk weight. Chowdhury et al. ${ }^{17}$ reported that egg yolk weight responded quadratically in weeks 3 and 4 with increasing levels of sun-dried garlic paste.

Inclusion of RG in the diets of laying chickens had no significant effect on egg shell weight and thickness of the birds, which probably suggests that RG did not affect the calcium to phosphorus ratio and metabolism in the layers' diets as the level of calcium and phosphorus are important in layers diet for the formation of egg shell. The results of this present study corroborate the findings of the previous research work by Khan et al. ${ }^{21}$ who observed no significant difference among treatment groups when white Leghorn layers were fed $0,2,6,8 \%$ garlic powder. Lim et al..$^{20}$ earlier reported no significant changes in egg shell thickness when 
Asian J. Anim. Vet. Adv., 13 (3):210-217, 2018

Table 5: Linear regression of serum lipids and egg cholesterol on dietary raw garlic in laying hens

\begin{tabular}{|c|c|c|c|c|c|c|c|}
\hline Parameters & Constant & Garlic $(r=0.80)$ & $\mathrm{t}$-value & $p$-value & $\mathrm{R}^{2}$ & F-value & $p$-value \\
\hline Total cholesterol & $110.8(15.26)$ & $-5.10(3.91)$ & -1.31 & 0.260 & 0.30 & 1.72 & 0.2601 \\
\hline Triglycerides & $79.3(5.54)$ & $-1.66(1.42)$ & -1.17 & 0.307 & 0.25 & 1.37 & 0.3071 \\
\hline LDL-cholesterol & $65.3(15.92)$ & $-7.30(4.09)$ & -1.79 & 0.148 & 0.44 & 3.20 & 0.1481 \\
\hline HDL-cholesterol & $29.2(2.54)$ & $2.63(0.65)$ & 4.04 & 0.016 & 0.80 & 16.33 & 0.0156 \\
\hline Yolk-cholesterol & $13.5(1.17)$ & $-0.44(0.30)$ & -1.47 & 0.217 & 0.35 & 2.15 & 0.2165 \\
\hline
\end{tabular}

Hyline Brown layers were fed 0, 1, 3 and 5\% garlic powder for 5 weeks. There was no mortality during the experimental period. Yalcin et al..$^{18}$ also recorded no mortality upon feeding of layers with 0,5 and $10 \mathrm{~g} \mathrm{~kg}^{-1}$ garlic powder over a 22 weeks experimental period.

The $\mathrm{RG}$ reduced serum $\mathrm{TC}$ in the experimental birds which confirmed the hypocholesterolemic property of garlic as earlier reported ${ }^{21}$. In a related experiment, plasma cholesterol was reduced by $30 \%$ when rats were fed diets supplemented with 2 or $3 \%$ garlic powder ${ }^{10}$. The level of reduction of serum $\mathrm{TC}$ in this present study is higher than that reported by Khan et al. ${ }^{21}$ who recorded $1.7 \%$ reduction in serum TC when laying hens were fed $8 \%$ garlic powder. The difference in the level of reduction could be due to different preparations of garlic. However, Qureshi et al. ${ }^{29}$ reported that the equivalent of 1, 2, 4, 6 and $8 \%$ garlic paste reduced serum TC by 18, 21, 21, 24 and $25 \%$, respectively, in male broiler chickens. Similarly, in another study, Qureshi et al. ${ }^{8}$ also reported that serum cholesterol of White Leghorn pullets was reduced by $20-25 \%$ with supplementation of garlic paste, a solvent-extracted garlic pastes and commercial garlic oil. Such reduction with supplementation of garlic may be due to the inhibition of fatty acid synthesis as organic tellurium compounds and allicin found in garlic might contribute to lower serum cholesterol by inhibiting squalene epoxidase which is needed in the synthetic pathway of cholesterol. It may also be due reduction in major regulatory enzyme of cholesterol biosynthesis activity ${ }^{29-30}$. Sklan et al. ${ }^{9}$ also reported that the inclusion of $2 \%$ lyopholized garlic in chick diets depressed hepatic cholesterol levels in chicks, suggesting that feeding of garlic may downregulate liver cholesterol synthesis.

The observation in this study shows that serum Tg was significantly reduced by graded levels of $R G$ in layers' diet. This result corroborates the observations of Yeh and $\mathrm{Liu}^{31}$ reported $30 \%$ reduction in triacylglycerol when $2 \mathrm{~g} / 100 \mathrm{~g}$ of age garlic extract was supplemented in Sprague-Dawley rats' diet. The study also showed that the triacylglycerol-lowering effect of garlic might be explained in part by its inhibiting action on fatty acid synthesis. However, this present study recorded a higher decrease of $36.6 \%$ in serum $\mathrm{Tg}$ concentration at $3 \%$ inclusion level of RG fed to laying hens.

Although the effect of the inclusion of RG at $3 \%$ on serum $\mathrm{Tg}$ did not show any significant difference in serum $\mathrm{Tg}$ when compared to layers fed $4 \% \mathrm{RG}$. This indicate that inclusion of $3 \% \mathrm{RG}$ in the diet of laying hens might be enough to reduce the serum Tg maximally. On the contrary, Horton et $a / .^{32}$ and Ghasemi et a/.33 reported that Tg was not affected by garlic or a mixture of garlic and thyme. The low inclusion level of this herbal mixture could be responsible for its non-significant effect on Tg compared with this present study.

The increasing effect of garlic on serum HDL concentration is advantageous, because serum $\mathrm{HDL}$ inhibits oxidation of serum LDL and thus prevents formation of foam cells by promoting cholesterol efflux in the intima ${ }^{34}$. It was observed in this current study that the values of $\mathrm{HDL}$ concentration increased linearly in response to increasing levels of dietary garlic $(r=0.80)$ (Table 5$)$. In addition, an inverse relationship could be deduced from the values for serum cholesterol and HDL concentration. As the value of serum cholesterol decreased with increasing level of RG included in the layer's diet, the HDL concentration increased up to $4 \%$ RG inclusion. This observation suggests a direct relationship between the factors that could limit the production of serum TC and HDL concentration in laying hens. In general, the HDL concentrations tended to follow an inverse pattern from other lipids. This results also corroborates the findings of Aouadi et al..$^{35}$, who recorded a significant increase in the value of $\mathrm{HDL}$ when rats were fed $10 \%$ fresh garlic. However, Canogullari et al. ${ }^{27}$ did not observe any difference in the values of $\mathrm{HDL}$ when $0,0,5,1$ and $2 \%$ garlic powder were fed to layers, the effect which may be due to inclusion of lower doses of garlic.

The hypocholesterolemic effect of garlic was exhibited in layers fed 1,2,3, 4 and 5\% RG. The present study reflected that the LDL concentration decreased with increasing level of RG in the layers' diet. Similar results were observed by previous researchers ${ }^{7,29,36}$.

The reduction of the egg yolk cholesterol observed in this study tended to follow the pattern of reduction of LDL-cholesterol. All the laying hens fed RG had significantly lower egg yolk cholesterol compared with birds fed control diet. Qureshi et al. ${ }^{29}$ reported that the suppressive action of garlic could be evident at level of cholesterol biosynthesis, in that garlic could suppress HMG-CoA reductase, the effect of which could manifest in the reduction of LDL-cholesterol. Previous studies also reported that garlic resulted in a 
reduction in yolk cholesterol ${ }^{18}$. However, at $0.5 \%$ inclusion of garlic powder in layers diet did not exert reducing effect on egg yolk cholesterol ${ }^{18}$. The reduction of yolk cholesterol recorded in this study compared with the previous research works ${ }^{18,29}$ may be attributed to inclusion of high dosage of RG in this present study. Also, the contrast in the level of reduction of yolk cholesterol due to intake of garlic by laying hens may be associated with differences in the age and or strains of the experimental hens.

\section{CONCLUSION AND FUTURE RECOMMENDATION}

Inclusion of raw garlic had no effect on feed efficiency, average egg weight, egg mass, yolk weight, shell weight and shell thickens. Five percent RG inclusion resulted in reduced feed intake in the experimental laying hens while $2 \%$ inclusion of RG had the highest hen-house production.

Specific conclusion about the use of raw garlic as growth promoter for laying hens may not be ascertained through the findings of this study, further studies are therefore recommended to ascertain that.

\section{SIGNIFICANCE STATEMENTS}

Raw garlic at the inclusion levels improved high-density lipoprotein cholesterol but reduced total cholesterol, yolk cholesterol and low-density lipoprotein cholesterol contents in the experimental animals. This study further confirms the hypocholesterolemic effect of garlic and its use in animal and human nutrition for health improvement.

\section{REFERENCES}

1. Vorster, H.H., A.C., Beynen, G.M.B. Berger and C.S. Venter, 1995. Dietary cholesterol-the role of eggs in the prudent diet. S. Afr. Med. J., 85: 253-256.

2. Clarke, R., C. Frost, R. Collin, P. Appleby and R. Peto, 1997. Dietary lipids and blood cholesterol: Quantitative metaanalysis of metabolic ward studies. Br. Med. J., 314: 112-117.

3. Howell, W.H., D.J. McNamara, M.A. Tosca, B.T. Smith and J.A. Gaines, 1997. Plasma lipid and lipoprotein responses to dietary fat and cholesterol: A meta-analysis. Am. J. Clin. Nutr., 65: 1747-1764.

4. Stamler, J. and R. Shekelle, 1988. Dietary cholesterol and human coronary heart disease. The epidemiologic evidence. Arch. Pathol. Lab. Med., 112: 1032-1040.

5. Burke, V., Y. Zhao, A.H. Lee, E. Hunter and R.M. Spargo et al., 2007. Health-related behaviours as predictors of mortality and morbidity in Australian aborigines. Prev. Med., 44: 135-142.
6. Weggemans, R.M., P.L. Zock and M.B. Katan, 2001. Dietary cholesterol from eggs increases the ratio of total cholesterol to high-density lipoprotein cholesterol in humans: A metaanalysis. Am. J. Clin. Nutr., 73: 885-891.

7. Kim, Y.J., S.K. Jin and H.S. Yang, 2009. Effect of dietary garlic bulb and husk on the physicochemical properties of chicken meat. Poult. Sci., 88: 398-405.

8. Qureshi, A.A., N. Abuirmeileh, Z.Z. Din, C.E. Elson and W.C. Burger, 1983. Inhibition of cholesterol and fatty acid biosynthesis in liver enzymes and chicken hepatocytes by polar fractions of garlic. Lipids, 18: 343-348.

9. Sklan, D., Y.N. Burner and H.D. Rabinowitch, 1992. The effect of dietary onion and garlic on hepatic lipid concentrations and activity of antioxidative enzymes in chicks. J. Nutr. Biochem., 3: 322-325.

10. Chi, M.S., E.T. Koh and T.J. Stewart, 1982. Effects of garlic on lipid metabolism in rats fed cholesterol or lard. J. Nutr., 112: 241-248.

11. Li, M., Y.X. Yan, Q.T. Yu, Y. Deng and D.T. Wu et al., 2017. Comparison of immunomodulatory effects of fresh garlic and black garlic polysaccharides on RAW 264.7 macrophages. J. Food Sci., 82: 765-771.

12. North, M.O., 1984. Breeder Management. In: Commercial Chicken Production Manual, North, M.O. (Ed.). The Avi Publishing Co. Inc., Westport, Connecticut, pp: 240-243.

13. Friedewald, W.T., R.I. Levy and D.S. Fredrickson, 1972. Estimation of the concentration of low-density lipoprotein cholesterol in plasma, without use of the preparative ultracentrifuge. Clin. Chem., 18: 499-502.

14. Lawson, L.D., D.K. Ransom and B.G. Hughs, 1992. Inhibition of whole blood platelet-aggregation by compounds in garlic clove extracts and commercial garlic products. Thromb. Res., 65: 141-156.

15. Cullen, S.P., F.J. Monahan, J.J. Callan and J.V. O'Doherty, 2005. The effect of dietary garlic and rosemary on grower-finisher pig performance and sensory characteristics of pork. Irish J. Agric. Food Res., 44: 57-67.

16. Olobatoke, R.Y. and S.D. Mulugeta, 2011. Effect of dietary garlic powder on layer performance, fecal bacterial load and egg quality. Poult. Sci., 90: 665-670.

17. Chowdhury, S.R., S.D. Chowdhury and T.K. Smith, 2002. Effects of dietary garlic on cholesterol metabolism in laying hens. Poult. Sci., 81: 1856-1862.

18. Yalcin, S., E.E. Onbasilar, Z. Reisli and S. Yalcin, 2006. Effect of garlic powder on the performance, egg traits and blood parameters of laying hens. J. Sci. Food Agric., 86: 1336-1339.

19. Yalcin, S., L. Onbasilar, A. Sehu and S. Yalcin, 2007. The effects of dietary garlic powder on the performance, egg traits and blood serum cholesterol of laying quails. Asian-Aust. J. Anim. Sci., 20: 944-947. 
20. Lim, K.S., S.J. You, B.K. An and C.W. Kang, 2006. Effects of dietary garlic powder and copper on cholesterol content and quality characteristics of chicken eggs. Asian-Aust. J. Anim. Sci., 19: 582-586.

21. Khan, S.H., R. Sardar and M.A. Anjum, 2007. Effects of dietary garlic on performance and serum and egg yolk cholesterol concentration in laying hens. Asian J. Poult. Sci., 1: 22-27.

22. Oluyemi, J.A. and F.A. Roberts, 2000. Poultry Production in Warm Wet Climates. 2nd Edn., Spectrum Books, Ibadan, Nigeria, ISBN-13: 9789780290979, pp: 18-34.

23. Ao, X., J.S. Yoo, J.H. Lee, H.D. Jang, J.P. Wang, T.X. Zhou and I.H. Kim, 2010. Effects of fermented garlic powder on production performance, egg quality, blood profiles and fatty acids composition of egg yolk in laying hens. Asian-Aust. J. Anim. Sci., 23: 786-791.

24. Mohebbifar, A. and M. Torki, 2010. Effects of adding mixed powder of garlic and thyme to diets included graded levels of rice bran on productive performance of laying hens and egg quality characteristics. Adv. Environ. Biol., 4: 469-476.

25. Rahardja, D.P., M.R. Hakim, W. Pakiding and V.S. Lestari, 2010. Hypocholesterolemic effect of garlic powder in laying hen: Low cholesterol egg? J. Indonesian Trop. Anim. Agric., 35: 16-21.

26. Khan, S.H., S. Hasan, R. Sarda and M.A. Anjum, 2008. Effects of dietary garlic powder on cholesterol concentration in native desi laying hens. Am. J. Food Technol., 3: 207-213.

27. Canogullar, S., M. Karaman, Z. Erdogan, M. Baylan, A. Kucukgul, V.V. Duzguner and A.K. Ozugur, 2009. Effect of garlic powder on egg yolk and serum cholesterol and performance of laying hens. Bull. Vet. Inst. Pulawy, 53: 515-519.

28. Mottaghitalab, M. and Z. Taraz, 2004. Garlic powder as blood serum and egg yolk cholesterol lowering agent. J. Poult. Sci., 41: 50-57.
29. Qureshi, A.A., Z.Z. Din, N. Abuirmeileh, W.C. Burger, Y. Ahmad and C.E. Elson, 1983. Suppression of avian hepatic lipid metabolism by solvent extracts of garlic: Impact on serum lipids. J. Nutr., 113: 1746-1755.

30. Konjufca, V.H., G.M. Pesti and R.I. Bakalli, 1997. Modulation of cholesterol levels in broiler meat by dietary garlic and copper. Poult. Sci., 76: 1264-1271.

31. Yeh, Y.Y. and L. Liu, 2001. Cholesterol-lowering effect of garlic extracts and organosulfur compounds: Human and animal studies. J. Nutr., 131: 989S-993S.

32. Horton, G.M.J., M.J. Fennell and B.M. Prasad, 1991. Effect of dietary garlic (Allium sativum) on performance, carcass composition and blood chemistry changes in broiler chickens. Can. J. Anim. Sci., 71: 939-942.

33. Ghasemi, R., M. Zarei and M. Torki, 2010. Adding medicinal herbs including garlic (Allium sativum) and thyme (Thymus vulgaris) to diet of laying hens and evaluating productive performance and egg quality characteristics. Am. J. Anim. Vet. Sci., 5: 151-154.

34. Mackness, M.I., S. Arrol, C. Abbott and P.N. Durrington, 1993. Protection of low-density lipoprotein against oxidative modification by high-density lipoprotein associated paraoxonase. Atherosclerosis, 104: 129-135.

35. Aouadi, R., A. Aouidet, A. Elkadhi, M.C.B. Rayana, H. Jaafoura, B. Tritar and K. Nagati, 2000. Effect of fresh garlic (Allium sativum) on lipid metabolism in male rats. Nutr. Res., 20: 273-280.

36. Bamidele, O. and I.O. Adejumo 2012. Effect of garlic (Allium sativum L.) and ginger (Zingiber officinale Roscoe) mixtures on performance characteristics and cholesterol profile of growing pullets. Int. J. Poult. Sci., 11: 217-220. 